\title{
A Class of Multi-Attribute Auction Transformed into Single-Attribute Auction on Margin Bid
}

Muhammad Farhan Bashir*

Business Administration, Central South University, Changsha, Hunan, P.R. China

\begin{abstract}
Designing a multi-attribute auction can have many advantages especially in concerning different attributes besides price. Nevertheless, the complexity of this method makes it hard to carry out the optimal mechanism. This paper combines the first sealed auction mechanism with multi-attribute auction, and gives a method of transforming multi-attribute auction into single-attribute auction by bidding in deposit. The analysis indicates that this method can just not only reduces the transaction risk caused by suppliers who will abandon the bid, but also makes the multi-attribute auction more easier to implement and operate; Besides, the method meets the incentive compatibility and participation constraint conditions under which the highest bidding supplier will win the auction; On the other hand, it also shows that equilibrium price and equilibrium quality increase as the efficiency parameter increase, but equilibrium delivery time increase when it decrease. More importantly, it is really interesting and inspiring that this method can bring more expected profits to the buyer comparing with traditional auction.
\end{abstract}

Keywords: Multi-attribute auction; Single-attribute auction; Cash deposit; Incentive compatibility

\section{Introduction}

Auction mechanisms have been widely used in electricity procurement and other fields [1], and recent economic developments have resulted in China becoming one of the largest public procurement markets in the world. This particular research focuses on the reverse auction, which mainly consists of government procurement, as the single-attribute price auction can't meet the requirements of bulk procurement on the attributes of quality, delivery time, aesthetic characteristics and service level, thus resulting in the practice of multiattribute auction at broader scale [2].

Multi-attribute auction has greater applicability than singleattribute auction, but the complexity of the mechanisms leads to relatively slow developments in the process of procurement. Like as in many procurement activities, if the single-attribute auction mechanism is used to determine the transaction only by price, non-price attributes such as quality cannot be guaranteed to meet the requirements; and if the multi-attribute auction mechanism is used to bid for each attribute, and the auction problem becomes complicated than standardized procedure.

In view of the above problems, this article takes into account the advantages of single-attribute auction and multi-attribute auction, combines the first-order sealed auction mechanism with the multiattribute auction mechanism, and presents a class of margin bidding method that transforms multi-attribute auction into single-attribute auction. The mechanism of this method is designed as: each supplier cannot bid more than its net profit (which is the supplier's private information).

In this research, when the purchaser is the winner of the margin bid, the supplier bids the margin according to the game logic of the first price-sealed auction. The buyer, based on the supplier's bid for the margin, decides who wins the bid. And the buyer uses the game logic of the multi-attribute auction mechanism to infer with the latter's technical type and calculates the equilibrium attribute value of the corresponding product, including the price, quality, late delivery, etc. As these equilibrium attribute values are obtained under the condition of the supplier's participation constraint and incentive compatibility constraint, Therefore, the rational supplier will accept the purchaser's requirement for the product and the successful transaction.

Compared with the traditional multi-attribute auction methods, by introducing a new margin of bidding decision variables the novelty of this paper lies in:

(1) The conversion of complex multi-attribute bidding into singleattribute bidding without the need to determine the scoring function of multi-attribute auction, which makes multi-attribute auction easier to operate and implement, also being able to reduce transaction risk.

(2) Still can guarantee the most advanced technical supplier win the bid. And under the condition of equilibrium, the value of each attribute of the final transaction is consistent with the corresponding attribute values of the traditional multi-attribute auction mechanism, but the purchaser can obtain a relatively larger expected return.

Assume that the purchaser in the "China government Procurement Network" and other web platforms to publish their own procurement requirements plan, and the auction method is the first price sealed auction. In addition, considering the importance of delivery attribute in the multi-attribute sourcing auction is likely to be second only to the quality attribute, a multi-attribute reverse auction model of margin bidding is constructed here, including the three attributes of price, quality and delivery time. The auction process between buyers and suppliers is designed as a three-phase: In the first stage, before the tender starts, the purchaser first announces the minimum bid margin $V_{0}$ (starting price), and the quality value factor of the purchase item $w_{1}$, the delivery value factor $w_{2}$, the latest delivery $\mathrm{L}$ and the expected quality,

*Corresponding author: Muhammad Farhan Bashir, Business Administration, Central South University, Changsha, Hunan, P.R. China, Tel: +8613272487055; E-mail: farhan.paks@csu.edu.cn

Received April 09, 2018; Accepted May 16, 2018; Published May 23, 2018

Citation: Bashir MF (2018) A Class of Multi-attribute Auction Transformed into Single-Attribute Auction on Margin Bid. Bus Eco J 9: 352. doi: 10.4172/21516219.1000352

Copyright: @ 2018 Bashir MF. This is an open-access article distributed under the terms of the Creative Commons Attribution License, which permits unrestricted use, distribution, and reproduction in any medium, provided the original author and source are credited. 
and so on.; In the second phase, within the prescribed time, the bidding enterprise shall bid on the margin according to its own technical type and other relevant information; In the third stage, the purchaser selects the supplier with the highest margin bid as the auction winner and asks for payment of the margin (the deposit will not be refunded when the supplier delivers the product, and only the successful bidder will pay the deposit) At this stage, the supplier will make a payment request to the purchaser according to the price determined by the model, and the purchaser shall provide the corresponding product according to the quality and lead time determined by the model. Because the mechanism of this paper is based on to meet the constraints of supplier participation and incentive compatibility under the goal of maximizing social net welfare, suppliers and purchasers will eventually agree to each other's requirements.

\section{Literature Review}

Much of the research on multi-attribute auction theory is based on the work of Che [3], such as the risk types of buyers and sellers, the collusion in auction and the remuneration of third-party auction houses. In order to study multi-attribute auction, Che [3] built a twodimensional model of government bidding and procurement, which set the basic research direction and ideas for multi-attribute auction as the ground breaking literature. Further studies by Che [3] and Leonardo [4] show that auctioneers can devise a function for deviation score in the form of a utility function that enhances the competition between bidders and thus brings greater revenue to the auctioneer. Based on aforementioned research, Che [3], Branco [5] studied the optimal mechanism for maximizing the total social surplus, assuming that the bidders' costs are correlated.

Jun and Shulin [6] used Cobb-Douglas utility function to discuss the impact on the equilibrium bidding strategy in a situation when suppliers showed different risk perception and compared the expected utility of the buyers with different risk perceptions. Tian and Chen [7] used the Arrow-Pratt measure to study the situation when both buyer and seller were risk averse and discussed the profit distribution between the two parties under cooperative and non-cooperative conditions.

Fugger et al. [8] studied the possibility of collusion in the auction. The experimental results show that when the bidder increases or the uncertainty variable declines, the probability of forming a collusive price will decrease. When considering third-party agencies, Ge and Whinston [9] argued that in order to effectively prevent collusion, buyers in addition to paying the auctioneer a fixed fee, should pay an extra payment to the auctioneer.

With the rise of e-commerce in developing economies, Kauffman and wood [10] studied the online fraudulent behavior which is easy to appear on the internet auction. Bichler [11] and Chen-Ritzo et al. [12] conducted empirical research based on auction websites. The results pointed towards the fact that multi-attribute auction can bring greater utility to buyers and sellers in comparison to single-attribute auction. Li et al. [13] research shows that by optimizing contract parameters, retailers can continuously reduce the cost of information, and retailers can overcome the problem of asymmetric information to maximize supply chain profits under specific conditions.

Wang's [14] work, who researched about the fact that online auction have the characteristics of entering time randomness and ending the auction at the end, shows that the higher the value of the product, the better the bidder's valuation of the goods will be suitable for the online auction. Haruvy and Katok [15] conducted and analyzed the results of empirical research, found that online purchasing auction tendered the price, whereas exogenous quality bids affected the winner's choices. They also found that by using the first-price auction, the method of sealed auction carries greater chances for benefit of buyer than using public auction method.

Designing a reasonable model to make it more realistic and effectively application to practice is the key to the auction theory [16]. David et al. [17] extended the multi-attribute auction to any number of attribute scenarios, and the article also made a corresponding study on the determination of the scoring function when the buyer profited the most. Based on the research by David et al. [17], Yahui and Yuqiang [18] proposed an improved multi-attribute auction model to make it more applicable and give a balanced bidding strategy for this model. In the theory of single-attribute auction, Vickrey [19], Myerson [20], Riley and Samuelson [21] showed that the four typical auction patterns give buyers the same expected return. Asker and Cantillon [22] show that this expectation of equal returns also exists in the multi-attribute auction. Later, David et al. [17] proved that the expected profit in the multi-attribute auction by using theorem. Xianke and Yuqiang [23] used the improved model to re-prove the theorem.

Common multi-attribute auction model mostly utilizes power function form. Shengbao [24] constructed a power function formal auction model, and used the model to study the British auction mechanism, the final analysis showed that the seller with the lowest cost resulted in winning the bid. For the more specific quasi-linear utility function model, Kersten's [25] study shows that the multi-attribute auction can be equivalent to the single-attribute auction under the condition that there is a unique solution to the given inequality in the article, and it will produce valid results when the auction focuses on preferences rather than quasi-linear functions invalid mechanism. Xueguang and Long [26] established a three-dimensional linear model with delivery time and introduced a fixed bidding cost variable in the model. The research's empirical findings indicated that raising the fixed bidding cost is beneficial to the purchaser, and the suppliers will get better gradually, as the fixed bidding cost increases.

While evaluating reasonable setting of scoring function in multiattribute auction, it is particularly important to evaluate bids. Beil and Wein [27] designed a multi-wheel multi-attribute reverse auction mechanism to infer the cost function information of suppliers, so as to determine the optimal scoring function to maximize its utility. Yang et al. [28] considered that knowing of the buyer's preference is the key to winning the bid, and put forwarded a model to induce buyer's preference information. Wang and Liu [29] designed a new weighted scoring function to solve the problem of dimensional inequality in traditional scoring functions, which makes the design model applicability very strong, however, it is assumed that the marginal cost of quality is not in line with reality. Wang [30] also uses conditional payment to replace the scoring function, but his research shows that the supplier's equilibrium price is equal to its own income, which can be further refined with the actual situation.

Single-attribute auction has the natural advantage in the bidding decisions. Holmstorm [31] and Myerson [32] and first proposed the problem of the optimal single-attribute auction. Which is that if a buyer can pick out all possible expansion mechanisms, which one should he use to sell a single indivisible item to maximize his expected return. In order to solve this problem, Kalpan and Zamir [33] proposed a lemma in 2013, in which the yield formula established applies to the returns of all feasible extension mechanisms under the Bayes-Nash equilibrium and is also the upper bound of the expected return of either mechanism. 
He also proved that the standard auction design with the appropriate reserve price would sometimes fetch this upper bound. Morales and Steinberg [34] studied the issues raised by Vickrey [19] in an article published in 1961, in doing so the author added a minimum limit to the bid constraints. Araujo and Moreira [35] think that in order to reduce the purchase cost, some enterprises will use a program that will result in multiple winners in the auction. However, in fact, a standard auction with multiple winners will result in the buyer paying a higher cost.

\section{Model and Basic Assumptions}

First of all, it must be pointed out that there are two economic implication of margin: the first deposit is essentially a type of "price", which means that the bidding enterprise does not exceed the size of the "price" that it is willing to pay for winning the bid project, which is the net gain of the bidding enterprise in obtaining the subject production item: $p_{i}-c\left(q_{i}, l_{i}, \theta_{i}\right)$; the second deposit is a kind of guarantee fund, which can reduce the transaction risk caused by abandoning the bid. The first economic meaning of the margin is the basis for the supplier to bid on the margin.

The first price sealed auction mechanism, that is, suppliers bid on the margin, the highest bidder to win the auction, and pay the appropriate security deposit, which is not returned after the success of the auction.

Assumption 1: In auction, there is a buyer and $\mathrm{n}$ suppliers. Buyers and suppliers are risk-neutral and have full information.

Assumption 2: Suppose that the quality $q$ and delivery date 1 of supplier-supplied product are independent of each other, and the quality $\mathrm{q}$ and delivery time 1 are both determined by the technology type $\theta$. Furthermore suppose that the supplier of technology type $\theta_{i}$ obeys $[\underline{\theta}, \bar{\theta}]$. The distribution function is $f\left(\theta_{i}\right)=\frac{1}{\bar{\theta}-\underline{\theta}}$, the density function is $F\left(\theta_{i}\right)=\frac{\theta_{i}-\underline{\theta}}{\bar{\theta}-\theta}$, Item information for buyers know.

Assumption 3: Suppose that the net utility function of supplier $i$ is:

$$
\begin{aligned}
& =p v\left(\theta_{i}\right)\left(\theta_{i}\right)-\frac{1}{\theta_{i}}\left[k_{1} q^{t_{1}}\left(\theta_{i}\right)+k_{2}\left(L-l\left(\theta_{i}\right)\right)^{t_{2}}\right] \\
& =p_{i}-c\left(q_{i}, l_{i}, \theta_{i}\right)
\end{aligned}
$$

Where $k_{1}, k_{2}$ are greater than zero, the supplier is given the weight of attribute $q_{i}$ and attribute $l_{i}$. To satisfy $c_{q}>0, c_{q q}>0$ and $c_{l}<0, c_{l l}>0$ has $t_{1} \geq 1, t_{2} \geq 1$. And pi is a shorthand way of $p\left(\theta_{i}\right)$, and the subsequent similar forms have the same meanings. When supplier $i$ bid on margin $V\left(\theta_{i}\right)$ that is not to be returned, the expected return is:

$$
\pi\left(\theta_{i}\right)=\left[p\left(\theta_{i}\right)-c\left(q\left(\theta_{i}\right), l\left(\theta_{i}\right), \theta_{i}\right)\right] \operatorname{prob}\left[V\left(\theta_{-i}\right)<V\left(\theta_{i}\right)\right]
$$

Where $\theta_{-i}$ denotes the set of arbitrary bidders except supplier $i$, that is $\theta_{-i}=\left(\theta_{1}, \theta_{2}, \cdots, \theta_{i-1}, \theta_{i+1}, \cdots, \theta_{n}\right)$. When a bidding firm with a true technical type of $\theta_{i}$ reports that, its technical type is $\mathrm{x}(\mathrm{t}$ that is, when the supplier negotiates the product quality and so on with the purchase), the expected return is:

$$
\pi\left(\mathrm{x}, \theta_{i}\right)=\left[p(x)-c\left(q(x), l(x), \theta_{i}\right)\right] \operatorname{prob}\left[V\left(\theta_{-i}\right)<V\left(\theta_{i}\right)\right]
$$

The incentive compatibility constraints is:

$$
\forall x, \theta_{i} \in[0,1], \pi\left(\theta_{i}, \theta_{i}\right) \geq \pi\left(x, \theta_{i}\right)
$$

$\pi\left(\theta_{\mathrm{i}}, \theta_{\mathrm{i}}\right)$ indicates that the bidding company whose technical type is $\theta_{\mathrm{i}}$ reports its own technical type as $\theta_{i}$.

This also need to meet the participation constraints:

$$
\pi\left(\theta_{i}\right)=\left[p\left(\theta_{i}\right)-c\left(q\left(\theta_{i}\right), l\left(\theta_{i}\right), \theta_{i}\right)\right] \operatorname{prob}\left[V\left(\theta_{-i}\right)<V\left(\theta_{i}\right)\right] \geq 0
$$

Suppose the utility function of buyers is:

$$
\begin{aligned}
& U_{i}=\omega_{1} q^{S_{1}}\left(\theta_{i}\right)+\omega_{2}\left(L-l\left(\theta_{i}\right)\right)^{S_{2}}-p\left(\theta_{i}\right)+V\left(\theta_{i}\right) \\
& =R\left(q_{i}, l_{i}\right)-p_{i}+V_{i}
\end{aligned}
$$

Where $\omega_{1}, \omega_{2}$ are both greater than zero, giving the purchaser the weight of attribute $\mathrm{q}_{\mathrm{i}}$ and attribute $\mathrm{l}_{\mathrm{i}} .0<\mathrm{S}_{1} \leq 1,0<\mathrm{S}_{2} \leq 1$ In order to meet $\mathrm{R}_{\mathrm{q}}>0, \mathrm{R}_{\mathrm{qq}}<0$ and $\mathrm{R}_{\mathrm{l}}<0, \mathrm{R}_{\mathrm{ll}}<0$.

\section{Equilibrium Binding Strategy}

Theorem 1: In the multi-attribute reverse auction of margin bidding, given the information such as the technical type parameter $\theta_{i}$ of the supplier, the bidder's bid $V\left(\theta_{i}\right)$ (bidding strategy) for the margin is:

$$
V_{i}=\frac{n-1}{n} v_{i}=\frac{n-1}{n}\left[p_{i}-c\left(q_{i}, l_{i}, \theta_{i}\right)\right]
$$

Proof: It is proved that the margin is a function about its own utility in the form of $V\left(v\left(\theta_{i}\right)\right)$ because the supplier determines the bidding margin according to its own net proceeds at the time of bidding. However, the final expression is a function on the technical type, that is $V\left(\theta_{i}\right)$.

Knowing the probability of winning:

$\operatorname{prob}\left[\mathrm{V}\left(\theta_{-\mathrm{i}}\right)<\mathrm{V}\left(\theta_{\mathrm{i}}\right)\right]=\operatorname{prob}\left[\mathrm{V}\left(\mathrm{v}_{-\mathrm{i}}\right)<\mathrm{V}\left(\mathrm{v}_{\mathrm{i}}\right)\right]=\operatorname{prob}\left[\mathrm{v}_{-\mathrm{i}}<\mathrm{V}^{-1}\left(\mathrm{~V}\left(\mathrm{v}_{\mathrm{i}}\right)\right)\right]$

$=\mathrm{F}^{\mathrm{n}-1}\left(\mathrm{~V}^{-1}\left(\mathrm{~V}\left(\mathrm{v}_{\mathrm{i}}\right)\right)\right.$

Make $\mathrm{F}^{\mathrm{n}-1}\left(\mathrm{~V}^{-1}\left(\mathrm{~V}\left(\mathrm{v}_{\mathrm{i}}\right)\right)\right)=\Phi^{\mathrm{n}-1}\left(\mathrm{~V}_{\mathrm{i}}\right)_{0}$

The expected return of the supplier can be expressed as:

$\pi\left(\theta_{\mathrm{i}}\right)=\left[\mathrm{v}\left(\theta_{\mathrm{i}}\right)-V\left(\theta_{i}\right)\right] \Phi^{n-1}\left(V_{i}\right)$

The optimal first-order condition for bidding to maximize $\pi\left(\theta_{\mathrm{i}}\right)$ is:

$-\Phi\left(V_{i}\right)+\left[v_{i}-V_{i}\right](\mathrm{n}-1) \Phi^{\prime}\left(V_{i}\right)=0$

In equilibrium $F\left(V^{-1}\left(V\left(v_{i}\right)\right)\right)=\Phi\left(V_{i}\right)=F\left(v_{i}\right)=\frac{v_{i}-\underline{\theta}}{\bar{\theta}-\underline{\theta}}$, where $\mathrm{F}$ is the final form of the function of $\theta_{\mathrm{i}}$ is $\mathrm{F}\left(\theta_{\mathrm{i}}\right)$. It can be seen (1) can be transformed into:

$$
-\Phi\left(V_{i}\right)+\left[\underline{\theta}+(\bar{\theta}-\underline{\theta}) \Phi\left(V_{i}\right)-V_{i}\right](\mathrm{n}-1) \Phi^{\prime}\left(V_{i}\right)=0
$$

Solution (2) to determine the differential equation, have:

$$
\begin{aligned}
& V\left(\theta_{i}\right)=V_{i}=\frac{n-1}{n}\left[(\bar{\theta}-\underline{\theta}) \Phi\left(V_{i}\right)+\underline{\theta}\right] \\
& =\frac{n-1}{n} v_{i}=\frac{n-1}{n}\left[p_{i}-c\left(q_{i}, l_{i}, \theta_{i}\right)\right]
\end{aligned}
$$

The best bid on margin is $\mathrm{V}_{i}=\frac{n-1}{n}\left[p_{i}-c\left(q_{i}, l_{i}, \theta_{i}\right)\right]$

Theorem 2: After the end of the auction process, in the third stage of this paper, the asking price $p\left(\theta_{i}\right)$ proposed by the supplier to the buyer according to the project information is:

$$
p\left(\theta_{i}\right)=c\left(q_{i}, l_{i}, \theta_{i}\right)-{ }_{\underline{\theta}}^{\theta_{i}} c_{\theta}(q, l, \theta)\left[\frac{F(\theta)}{F\left(\theta_{i}\right)}\right]^{n-1} d \theta
$$

Proof: Since the expected profit of supplier $i$ is:

$$
\pi\left(\theta_{i}\right)=\frac{1}{n}\left[p\left(\theta_{i}\right)-c\left(q\left(\theta_{i}\right), l\left(\theta_{i}\right), \theta_{i}\right)\right] F^{n-1}\left(\theta_{i}\right)
$$

Therefore, when a supplier of true technology type $\theta_{i}$ does not hide information and reports his own type as $\theta_{i}$, the expected profit 
is: $\pi\left(\theta_{i} \theta_{i}\right)=\pi\left(\theta_{i}\right)$. When the supplier with hidden information of real technology type $\mathrm{x}$ misrepresents itself as $\theta_{i}$, its expected profit is:

$$
\pi\left(\theta_{i}, x\right)=\frac{1}{n}\left[p\left(\theta_{i}\right)-c\left(q\left(\theta_{i}\right), l\left(\theta_{i}\right), x\right)\right] F^{n-1}\left(\theta_{i}\right)
$$

Also $\pi\left(\theta_{i}, \theta_{i}\right)-\pi\left(x, \theta_{i}\right)=\frac{1}{n}\left[c\left(q\left(\theta_{i}\right), l\left(\theta_{i}\right), x\right)-c\left(q\left(\theta_{i}\right), l\left(\theta_{i}\right), \theta_{i}\right)\right] F^{n-1}\left(\theta_{i}\right)$

When $x \rightarrow \theta$, the above equation can be changed into

$$
\frac{d \pi\left(\theta_{i}, \theta_{i}\right)}{d \theta_{i}}=\frac{d \pi\left(\theta_{i}\right)}{d \theta_{i}}=-\frac{1}{n} c_{\theta}\left(q_{i}, l_{i}, \theta_{i}\right) F^{n-1}\left(\theta_{i}\right)
$$

Where $c_{\theta}\left(q_{i} l_{i}, \theta_{i}\right)$ means that $c\left(q_{i} l_{i}, \theta_{i}\right)$ derives the third term $\theta_{i}$ in brackets, that is:

$$
c_{\theta}\left(q_{i}, l_{i}, \theta_{i}\right)=-\frac{1}{\theta_{i}^{2}}\left[k_{1} q^{t_{1}}\left(\theta_{i}\right)+k_{2}\left(L-l\left(\theta_{i}\right)\right)^{t_{2}}\right] .
$$

The same forma of the following formula has the same meaning for (4) about the type of integration on both sides, then there

$$
\begin{aligned}
& \pi\left(\theta_{i}\right)-\pi(\underline{\theta})=-\frac{1}{n}{ }_{i}^{\theta_{i}} c_{\theta}(q, l, \theta) F^{n-1}(\theta) d \theta \\
& \text { Since } \pi(\underline{\theta})=0 \text {, then } \pi\left(\theta_{i}\right)=-\frac{1}{n}{ }_{j}^{\theta_{i}} c_{\theta}(q, l, \theta) F^{n-1}(\theta) d \theta
\end{aligned}
$$

By combing eqns. (3) and (5). The available asking price $p\left(\theta_{i}\right)$ provided by the supplier to the purchaser is:

$$
p\left(\theta_{i}\right)=c\left(q_{i}, l_{i}, \theta_{i}\right)-{ }_{\underline{\theta}}^{\theta_{i}} c_{\theta}(q, l, \theta)\left[\frac{F(\theta)}{F\left(\theta_{i}\right)}\right]^{n-1} d \theta
$$

Theorem 3: In the reverse multi-attribute auction of margin bid satisfies the incentive compatibility constraint, and the profit, expected by the supplier when the information, is fully disclosed.

Proof: When the real technology type is, $\theta_{i}$ the supplier hides the information and misrepresents that the type is $x$, the expected profit is:

$$
\begin{aligned}
& \pi\left(x, \theta_{i}\right)=\frac{1}{n}\left[p(x)-c\left(q(x), l(x), \theta_{i}\right)\right] F^{n-1}(x) \\
& \text { also } p\left(\theta_{i}\right)=c\left(q\left(\theta_{i}\right), l\left(\theta_{i}\right), \theta_{i}\right)-{ }_{\underline{\underline{\theta}}}^{\theta_{i}} c_{\theta}(q(\theta), l(\theta), \theta)\left[\frac{F(\theta)}{F\left(\theta_{i}\right)}\right]^{n-1} d \theta \\
& \text { then } p(x)=c(q(x), l(x), x)-{ }_{\underline{\underline{\theta}}}^{x} c_{\theta}(q(\theta), l(\theta), \theta)\left[\frac{F(\theta)}{F(x)}\right]^{n-1} d \theta \\
& \text { therefore } \pi\left(x, \theta_{i}\right)=\frac{1}{n}\left[c(q(x), l(x), x)-c\left(q(x), l(x), \theta_{i}\right)\right] F^{n-1}(x) \\
& -\frac{1}{n} \underline{j}_{\underline{j}}^{x} c_{\theta}(q(\theta), l(\theta), \theta) F^{n-1}(\theta) d \theta \\
& \text { can know } \pi\left(\theta_{i}, \theta_{i}\right)-\pi\left(x, \theta_{i}\right)
\end{aligned}
$$$$
=-\frac{1}{n} \underline{{ }_{i}} c_{\theta}(q(\theta), l(\theta), \theta) F^{n-1}(\theta) d \theta+\frac{1}{n} \int_{\underline{\theta}}^{x} C_{\theta}(q(\theta), l(\theta), \theta) F^{n-1}(\theta) d \theta
$$$$
-\frac{1}{n}\left[c(q(x), l(x), x)-c\left(q(x), l(x), \theta_{i}\right)\right] F^{n-1}(x)
$$$$
\frac{1}{n}{ }_{\theta_{i}}^{x} c_{\theta}(q(\theta), l(\theta), \theta) F^{n-1}(\theta) d \theta-\frac{1}{n} \int_{\theta_{i}}^{x} c_{\theta}(q(x), l(x), \theta) F^{n-1}(x) d \theta
$$$$
=\frac{1}{n} \int_{\theta_{i}}^{x}\left[c_{\theta}(q(\theta), l(\theta), \theta) F^{n-1}(\theta)-c_{\theta}(q(x), l(x), \theta) F^{n-1}(x)\right] d \theta
$$

Suppose the mass $q(\theta)$ is an increasing function of the type of technology $\theta$, and the delivery time $l(\theta)$ is a decreasing function of the technology type $\theta$. (Theorem 6 shows the hypothesis holds) (i) When $x>\theta_{i}, \theta \varepsilon\left[\theta_{i}, x\right]$

By $q(x)>q(\theta), c_{\theta q}<0$ and $\mathrm{l}(\theta)>l(x), c_{\theta l}>0$, we have:

$c_{\theta}(q(\theta), l(\theta), \theta)>c_{\theta}(q(x), l(x), \theta)$

And since the distribution function $\mathrm{F}($.) increases with respect to the type of technology $\theta_{i}, F^{n-1}(x)>F^{n-1}(\theta)$

Can know: $c_{\theta}(q(\theta), l(\theta), \theta) F^{n-1}(\theta)>c_{\theta}(q(x), l(x), \theta) F^{n-1}(\theta)>c_{\theta}(q(x)$, $l(x), \theta) F^{n-1}(x)$

Which is: $\pi\left(\theta_{i}, \theta_{i}\right)-\pi\left(x, \theta_{i}\right)>0$

(ii) then $x<\theta_{i}, \theta \varepsilon\left[x, \theta_{i}\right]$

by $q(\theta)>q(x), c_{\theta q}<0$ and $l(x)>l(\theta), c_{\theta l}>0$, we have:

$c_{\theta}(q(\theta), l(\theta), \theta)<c_{\theta}(q(x), l(x), \theta)$

Can know: $c_{\theta}(q(\theta), l(\theta), \theta) F^{n-1}(\theta)<c_{\theta}(q(x), l(x), \theta) F^{n-1}(\theta)<c_{\theta}(q(x)$, $l(x), \theta) F^{n-1}(x)$

Which is: $\pi\left(\theta_{i}, \theta_{i}\right)-\pi\left(x, \theta_{i}\right)>0$.

The above proof shows that the supplier does not hide his true information, and the true profit is achieved, when he has obtained the information. Hence, the mechanism meets the incentive compatibility constraints.

Theorem 4: In the third stage of the auction, the optimal transaction attribute value proposed by the purchaser to the supplier is the same as the study of David et al. [17].

$$
\begin{aligned}
& p_{i}^{*}=c\left(q_{i}, l_{i}, \theta_{i}\right)-{ }_{\underline{\theta}}^{\theta_{i}} c_{\theta}(q, l, \theta)\left[\frac{F(\theta)}{F\left(\theta_{i}\right)}\right]^{n-1} d \theta \\
& q_{i}^{*}=\left(\frac{\omega_{1} \cdot S_{1} \cdot \theta_{i}}{k_{1} \cdot t_{1}}\right)^{\frac{1}{t_{1}-S_{1}}} \\
& l_{i}^{*}=L-\left(\frac{\omega_{2} \cdot S_{2} \cdot \theta_{i}}{k_{2} \cdot t_{2}}\right)^{\frac{1}{t_{2}-S_{2}}}
\end{aligned}
$$

Proof: The supplier will eventually accept the buyer's property requirements and provide the corresponding attributes of the product.

Proof Theorem 2 shows that the final transaction price

$$
p\left(\theta_{i}\right)=c\left(q_{i}, l_{i}, \theta_{i}\right)-{ }_{\underline{\theta}}^{\theta_{i}} c_{\theta}(q, l, \theta)\left[\frac{F(\theta)}{F\left(\theta_{i}\right)}\right]^{n-1} d \theta
$$

From the perspective of long-term cooperation and moral hazard reduction, rational purchasers need to maximize the profits of suppliers when designing the auction mechanism. The property values submitted by the suppliers also need to maximize the returns for the buyers. It can be seen that the optimal transaction quality and the best delivery that satisfy the principle of maximizing the total social wealth.

The total social income

$$
\mathrm{E}=\omega_{1} q^{S_{1}}\left(\theta_{i}\right)+\omega_{2}\left(L-l\left(\theta_{i}\right)\right)^{S_{2}}-\frac{1}{\theta_{i}}\left[k_{1} q^{t_{1}}\left(\theta_{i}\right)+k_{2}\left(L-l\left(\theta_{i}\right)\right)^{t_{2}}\right]
$$

Then the quality of the transaction:

$$
q_{i}^{*}=\operatorname{argmax}\left\{\omega_{1} q^{S_{1}}\left(\theta_{i}\right)+\omega_{2}\left(L-l\left(\theta_{i}\right)\right)^{S_{2}}-\frac{1}{\theta_{i}}\left[k_{1} q^{t_{1}}\left(\theta_{i}\right)+k_{2}\left(L-l\left(\theta_{i}\right)\right)^{t_{2}}\right]\right\}
$$

Delivered items delivery:

$$
l_{i}^{*}=\operatorname{argmax}\left\{\omega_{1} q^{S_{1}}\left(\theta_{i}\right)+\omega_{2}\left(L-l\left(\theta_{i}\right)\right)^{S_{2}}-\frac{1}{\theta_{i}}\left[k_{1} q^{t_{1}}\left(\theta_{i}\right)+k_{2}\left(L-l\left(\theta_{i}\right)\right)^{t_{2}}\right]\right\}
$$

For equation (5), respectively, and partial derivative, and make it equal to zero. Have: 


$$
\begin{aligned}
& q_{i}=\left(\frac{\omega_{1} \cdot S_{1} \cdot \theta_{i}}{k_{1} \cdot t_{1}}\right)^{\frac{1}{t_{1}-S_{1}}} \\
& l_{i}=L-\left(\frac{\omega_{2} \cdot S_{2} \cdot \theta_{i}}{k_{2} \cdot t_{2}}\right)^{\frac{1}{t_{2}-S_{2}}}
\end{aligned}
$$

From $\pi(\underline{\theta})=0$, we can see that the mechanism satisfies the participation constraint. In addition, the proof of Theorem 3 shows that the mechanism satisfies the incentive compatibility constraint, and the attribute value submitted by the supplier is the true value of the final delivery item.

\section{Winner's Determination}

Theorem 5: The multi-attribute reverse auction of margin bidding can effectively allocate resources, that is, the supplier with the most advanced technology type wins the auction with the highest margin bid.

Proof: It is proved that $q\left(\theta_{i}\right)>0, L-l\left(\theta_{i}\right)>0$ for any technical type $\theta_{i}$ because the price $p_{i}$ is a function of quality $q_{i}$ and delivery time $l_{i}$, the quality and delivery time are independent of other attribute values respectively.

In order to get the differential coefficients of $v\left(\theta_{i}\right)=p\left(\theta_{i}\right)-c\left(q\left(\theta_{i}\right), l\left(\theta_{i}\right), \theta_{i}\right)$ by $\theta_{i}$, we have:

$$
\begin{aligned}
& v^{\prime}\left(\theta_{i}\right)=p_{q} \cdot q^{\prime}\left(\theta_{i}\right)+p_{l} \cdot l^{\prime}\left(\theta_{i}\right)-c_{q} \cdot q^{\prime}\left(\theta_{i}\right)-c_{l} \cdot l^{\prime}\left(\theta_{i}\right)-c_{\theta} \\
& \left(p_{q}-c_{q}\right) q^{\prime}\left(\theta_{i}\right)+\left(p_{l}-c_{l}\right) l^{\prime}\left(\theta_{i}\right)-c_{\theta}
\end{aligned}
$$

Where $p_{q}$ denotes the partial derivative of the price $p_{i}$ to the mass $q_{i}$ (the meaning of the analogous form is the same)

As the supplier determines the tender for the margin according to its maximum net income, the equilibrium quality and the equilibrium price are satisfied with the principle of maximizing the supplier's net income when it exists: $v\left(\theta_{i}\right)$ about $q_{i}$ derivation and make it equal to 0 , have $p_{q}=c_{q}$; about $l_{i}$ derivation and make it equal to 0 , have $p_{l}=c_{l}$. The derivative of $v\left(\theta_{i}\right)$ about is $\theta_{i}: \mathrm{v}^{\prime}\left(\theta_{\mathrm{i}}\right)=-\mathrm{c}_{\theta}$

As a result of $\mathrm{v}^{\prime}\left(\theta_{\mathrm{i}}\right)=-\mathrm{c}_{\theta}>0$, and the vendor's bid for margin: $\mathrm{V}\left(\theta_{\mathrm{i}}\right)=\frac{\mathrm{n}-1}{\mathrm{n}} \mathrm{v}\left(\theta_{\mathrm{i}}\right)$ the margin is known as the technical type of the increment function, while the highest bidder for the margin bid can win the auction, so the technology-type supplier wins the auction.

Since the supplier determines the bid on the margin according to his own net income, the principle of maximizing the net income of the supplier when the equilibrium quality and the equilibrium price exist satisfies the following equation: $v\left(\theta_{i}\right)$ derive and make it equal to 0 for $q$ and $p_{q}=c_{q} ; l_{i}$ derivation and make it equal to 0 , there $p_{l}-c_{l}$. It can be seen that the derivative of $v\left(\theta_{i}\right)$ with respect to $\theta_{i}$ is: $v^{\prime}\left(\theta_{i}\right)=-c_{\theta}$.

Since $v^{\prime}\left(\theta_{i}\right)=-c_{\theta}>0$ and supplier bidding on margin: $\mathrm{V}\left(\theta_{i}\right)=\frac{n-1}{n} v\left(\theta_{i}\right)$ we can see that margin is an increasing function of technology type, The highest-bidder wins the auction, so the highesttech provider wins the auction.

A given buyer's revenue function $U_{i}=R\left(q_{i}, l_{i}\right)-p_{i}+V_{i}$, because $V_{i}=\frac{n-1}{n} v_{i}$, and $v_{i}=p_{i}-c\left(q_{i}, l_{i}, \theta_{i}\right)$ The buyer's expected return is: $\mathrm{EP}_{\text {buyer }}=\mathrm{E}\left[U_{i}\right]=\mathrm{E}\left[\mathrm{R}\left(q_{i}, l_{i}\right)-\frac{1}{n} p_{i}-\frac{n-1}{n} \mathrm{c}\left(q_{i}, l_{i}, \theta_{i}\right)\right]$, Order for convenience $f_{(1)}\left(\theta_{i}\right)=n F^{n-1}\left(\theta_{i}\right) f\left(\theta_{i}\right)_{0}$.

Theorem 6: Combined with the first price sealed auction and other information, The buyer's expected return $\mathrm{EP}_{\text {buyer }}$ can be calculated:

$$
E P_{\text {buyer }}=\int_{\underline{\theta}}^{\bar{\theta}}\left[R\left(q_{i}, l_{i}\right)-c\left(q_{i}, l_{i}, \theta_{i}\right)+\frac{1}{n} c_{\theta}\left(q_{i}, l_{i}, \theta_{i}\right) H\left(\theta_{i}\right)\right] f_{(1)}\left(\theta_{i}\right) d \theta_{i}
$$

Prove: The buyer's expected return is:

$$
\begin{aligned}
& \mathrm{EP}_{\text {buyer }}=\int_{\underline{\theta}}^{\bar{\theta}}\left[R\left(q_{i}, l_{i}\right)-\frac{1}{n} p_{i}-\frac{n-1}{n} c\left(q_{i}, l_{i}, \theta_{i}\right)\right] f_{(1)}\left(\theta_{i}\right) d \theta_{i} \\
& =\int_{\underline{\theta}}^{\bar{\theta}}\left[R\left(q_{i}, l_{i}\right)-c\left(q_{i}, l_{i}, \theta_{i}\right)+\frac{1}{n} \frac{j_{\underline{\theta}}}{\theta_{i}} c_{\theta}(q, l, \theta)\left(\frac{F(\theta)}{F\left(\theta_{i}\right)}\right)^{n-1} d \theta\right] f_{(1)}\left(\theta_{i}\right) d \theta_{i} \\
& =\int_{\underline{\theta}}^{\bar{\theta}}\left[R\left(q_{i}, l_{i}\right)-c\left(q_{i}, l_{i}, \theta_{i}\right)\right] f_{(1)}\left(\theta_{i}\right) d \theta_{i}+\frac{1}{n \underline{i} \underline{\theta} \underline{\theta} \theta_{i}} c_{\theta}(q, l, \theta) F^{n-1}(\theta) n f\left(\theta_{i}\right) d \theta d \theta_{i} \\
& =\int_{\underline{\theta}}^{\bar{\theta}}\left[R\left(q_{i}, l_{i}\right)-c\left(q_{i}, l_{i}, \theta_{i}\right)\right] f_{(1)}\left(\theta_{i}\right) d \theta_{i}+\underset{\underline{\theta} \theta}{\bar{\theta} \bar{\theta}} \mathcal{I}_{\theta}(q, l, \theta) F^{n-1}(\theta) f\left(\theta_{i}\right) d \theta_{i} d \theta \\
& =\underset{\underline{\theta}}{\bar{\theta}}\left[R\left(q_{i}, l_{i}\right)-c\left(q_{i}, l_{i}, \theta_{i}\right)+\frac{1}{n} c_{\theta}\left(q_{i}, l_{i}, \theta_{i}\right) H\left(\theta_{i}\right)\right] f_{(1)}\left(\theta_{i}\right) d \theta_{i}
\end{aligned}
$$$$
\text { We suppose } \mathrm{H}\left(\theta_{i}\right)=\frac{1-F\left(\theta_{i}\right)}{f\left(\theta_{i}\right)}
$$

\section{Optimal Auction Mechanism Implementation}

David et al. [17] showed that the maximum return expected by buyers depends on the number of people participating in the auction and the range of cost coefficients, and empirical model concludes that the quality of the products offered by the suppliers do not vary with the number of auction participants and the equilibrium price, and with more suppliers participate in the auction, this will result in lower price. Whether this paper also has a similar nature of the model of margin bidding, this part discusses and gives a proof. Moreover, the research in this paper shows that when the technology type of supplier is higher, the greater the income brought to the buyer, the supplier with the most advanced technology type wins the highest bid on the margin and wins the auction when it fulfills the contract. Therefore, we can conclude that the maximum return expected by the buyers in the margin model can be achieved.

Theorem 7: In the model with margin, the quality $\mathrm{q}_{\mathrm{i}}^{*}$ of the final transaction in the third stage and the delivery time $l_{i}^{*}$ will have nothing to do with the number of suppliers $n$ participating in the auction. The optimal transaction price $p_{i}^{*}$ decrease as the number of suppliers increases. And the optimal transaction price $p_{i}^{*}$ and the transaction quality $q_{i}^{*}$ will increase with the increase of technology type $\theta_{i}$. The transaction delivery time $l_{i}^{*}$ will decrease with the increase of technology type $\theta_{i}$.

Proof: Due to the fact that $q_{i}^{*}=\left(\frac{\omega_{1} \cdot S_{1} \cdot \theta_{i}}{k_{1} \cdot t_{1}}\right)^{\frac{1}{t_{1}-S_{1}}}$, the delivery time $l_{i}^{*}=L-\left(\frac{\omega_{2} \cdot S_{2} \cdot \theta_{i}}{k_{2} \cdot t_{2}}\right)^{\frac{1}{t_{2}-S_{2}}}$, we can see that the quality of the best deal and the delivery date are not related to the number of people who participated in the auction. And, the quality of transactions will increase with the type of technology increases, the delivery of the delivery will be as technology types increase. The optimal transaction price $p_{i}^{*}=c\left(q_{i}, l_{i}, \theta_{i}\right)-{ }_{\underline{\theta}}^{\theta_{i}} c_{\theta}(q, l, \theta)\left[\frac{F(\theta)}{F\left(\theta_{i}\right)}\right]^{n-1} d \theta$, for ease of calculation can be assumed $\underline{\theta}=0$, then: 


$$
\begin{aligned}
& p_{i}^{*}=\frac{1}{\theta_{i}}\left[k_{1}\left(\frac{\omega_{1} \cdot S_{1} \cdot \theta_{i}}{k_{1} \cdot t_{1}}\right)^{\frac{t_{1}}{t_{1}-S_{1}}}+k_{2}\left(\frac{\omega_{2} \cdot S_{2} \cdot \theta_{i}}{k_{2} \cdot t_{2}}\right)^{\frac{t_{2}}{t_{2}-S_{2}}}\right] \\
& +\underset{\underline{\theta}}{+\theta_{i}}\left[k_{1}\left(\frac{\omega_{1} \cdot S_{1} \cdot \theta}{k_{1} \cdot t_{1}}\right)^{\frac{t_{1}}{t_{1}-S_{1}}}+k_{2}\left(\frac{\omega_{2} \cdot S_{2} \cdot \theta}{k_{2} \cdot t_{2}}\right)^{\frac{t_{2}}{t_{2}-S_{2}}}\right] \cdot \theta^{n-3} d \theta / \theta_{i}^{n-1}
\end{aligned}
$$

We have:

$$
p_{i}^{*}=\left[1+\frac{t_{1}-S_{1}}{t_{1}+(n-2)\left(t_{1}-S_{1}\right)}\right] \cdot k_{1}\left(\frac{\omega_{1} S_{1}}{k_{1} t_{1}}\right)^{\frac{t_{1}}{1}-S_{1}} \theta_{i}^{\frac{S_{1}}{t_{1}-S_{1}}}+\left[1+\frac{t_{2}-S_{2}}{t_{2}+(n-2)\left(t_{2}-S_{2}\right)}\right] \cdot k_{2}\left(\frac{\omega_{2} \cdot S_{2}}{k_{2} \cdot t_{2}}\right)^{\frac{t_{2}-S_{2}}{2-S_{2}}} \theta_{i}^{\frac{S_{2}-S_{2}}{t_{2}}}
$$

It can be seen that the optimal transaction price decreases as the number of auction increases and increases as the type of technology increases.

Theorem 8: The multi-attribute reverse auction bidding on margin can achieve the goal of optimal auction mechanism design, and the supplier with most advanced technology at the auction can bring the maximum benefit to buyers.

Proof: As the buyer income is:

$$
\begin{aligned}
& U_{i}=R\left(q_{i}, l_{i}\right)-p_{i}+V_{i} \\
& =\omega_{1}\left(\frac{\omega_{1} \cdot S_{1} \cdot \theta_{i}}{k_{1} \cdot t_{1}}\right)^{\frac{S_{1}}{t_{1}-S_{1}}}+\omega_{2}\left(\frac{\omega_{2} \cdot S_{2} \cdot \theta_{i}}{k_{2} \cdot t_{2}}\right)^{\frac{S_{2}}{t_{2}-S_{2}}}-\frac{1}{n}\left[1+\frac{t_{1}-S_{1}}{t_{1}+(n-2)\left(t_{1}-S_{1}\right)}\right] . \\
& k_{1}\left(\frac{\omega_{1} \cdot S_{1}}{k_{1} \cdot t_{1}}\right)^{\frac{t_{1}}{t_{1}-S_{1}}} \frac{S_{1}}{\theta_{i}^{t_{1}-S_{1}}}-\frac{1}{n}\left[1+\frac{t_{2}-S_{2}}{t_{2}+(n-2)\left(t_{2}-S_{2}\right)}\right] \cdot k_{2}\left(\frac{\omega_{2} \cdot S_{2}}{k_{2} \cdot t_{2}}\right)^{\frac{t_{2}}{t_{2}-S_{2}}} \theta_{i}^{\frac{S_{2}}{t_{2}-S_{2}}} \\
& =\left[\frac{t_{1}}{S_{1}}-\frac{1}{n} \cdot \frac{t_{1}-S_{1}}{t_{1}+(n-2)\left(t_{1}-S_{1}\right)}-1\right] k_{1}\left(\frac{\omega_{1} S_{1}}{k_{1} t_{1}}\right)^{\frac{1}{1-S_{1}}} \theta_{i}^{\frac{s_{1}-S_{1}}{1}}+\left[\frac{t_{2}}{S_{2}}-\frac{1}{n} \cdot \frac{t_{2}-S_{2}}{t_{2}+(n-2)\left(t_{2}-S_{2}\right)}-1 k_{2}\left(\frac{\omega_{2} S_{2}}{k_{2} t_{2}}\right)^{\frac{t_{2}}{h_{2}-S_{2}}} \theta_{i}^{\frac{S_{2}}{t_{2}-S_{2}}}\right.
\end{aligned}
$$

Because $t_{i} \geq 1,0 \leq S_{i} \leq 1$, and $i=1,2_{o}$ then

$$
\begin{aligned}
& \frac{t_{i}}{S_{i}}-\frac{1}{n} \cdot \frac{t_{i}-S_{i}}{t_{1}+(n-2)\left(t_{i}-S_{i}\right)}-1 \\
& =\frac{t_{i}-S_{i}}{S_{i}}-\frac{t_{i}-S_{i}}{n} \frac{t_{i}+(n-)\left(t_{i}-S_{i}\right)}{n S_{i}\left[t_{i}+(n-2)\left(t_{i}-S_{i}\right)\right]} \cdot\left(t_{i}-S_{i}\right)>0
\end{aligned}
$$

We can see that the buyer's income is an increasing function of the technology type, that is, the supplier with the most advanced technology type can bring the maximum return to the buyer and the multi-attribute reverse auction bidding on the margin because the most advanced technology provider can win the auction Can achieve the goal of optimal mechanism design.

Theorem 9: This paper uses the first price sealed auction design bidding mechanism compared with the use of the true effectiveness of the buyer as a scoring function of the four traditional auction (first price sealed auction, second price sealed auction, Dutch auction, British auction), To give buyers greater expectations of revenue.

Proof: According to the solution formula of the product attribute value, the result of the attribute value obtained by the two types of auction methods is the same for the margin bidding and the bid evaluation score function. Given the model, assumptions and product attribute values are the same, the expected return of the buyer in the model using the true utility of the buyer as the score function is EPB [17]:

$$
\begin{aligned}
& E P_{B}=\int_{\underline{\theta}}^{\bar{\theta}}\left[R\left(q_{i}, l_{i}\right)-p_{i}\right] f_{(1)}\left(\theta_{i}\right) d \theta \\
& <E P_{\text {buyer }}=\int_{\underline{\theta}}^{\bar{\theta}}\left[R\left(q_{i}, l_{i}\right)-p_{i}+v_{i}\right] f_{(1)}\left(\theta_{i}\right) d \theta
\end{aligned}
$$

According to the same theorem of expected return, we can see that the four auction mechanisms that use the scoring function to bid for buyers are less than the expected return to the purchaser by using the first price sealed auction.

\section{Case Study}

In order to better verify the rationality of the model, this section will give a specific example analysis.

Here we suppose a famous hospital in order to better solve the doctor-patient problem, it is urgent need to purchase a large medical equipment. In view of the availability of medical equipment that affects the physical rehabilitation of patients with diseases, the relevant purchasing department expects the selection of suppliers in the procurement process to be as simple as possible. Nowadays, the forms of auction studied by scholars at home and abroad are divided into two types: single-attribute auction and multi-attribute auction. If the buyer uses the single-attribute auction then the supplier cannot guarantee the quality of the equipment, if the conventional method is used to check the quality of the equipment, time and price attributes of the tender and it seems cumbersome. It can be seen that using the mechanism designed in this paper to obtain high quality and low delivery time through the determination of margin bidding, and the reasonable price of medical equipment will be closer to the actual auction activities.

Suppose the existing 10 medical equipment suppliers to participate in the bidding, the 10 suppliers of medical equipment production technology types were $(0.09,0.16,0.22,0.31,0.42,0.56,0.62,0.73$, $0.85,0.97)$. Procurement department to complete the procurement task to obtain the value function is: $R\left(q_{i}, l_{i}\right)=q^{1 / 2}\left(\theta_{i}\right)+\left(1-\left(\theta_{i}\right)\right)^{1 / 2}$. The cost function of this piece of medical equipment is: $c\left(q_{i}, l_{i}, \theta_{i}\right)=\left[q^{2}\left(\theta_{i}\right)+(a-\right.$ $\left.\left.l\left(\theta_{i}\right)\right)^{2}\right] / \theta_{i}$. The other type [0.1] obeys the uniform distribution on $\theta_{i}$, and then $f\left(\theta_{i}\right)=1$, and $F\left(\theta_{i}\right)=\theta_{i}$. Combining the equilibrium property values in Theorem 4.

$$
\begin{aligned}
& p_{i}^{*}=c\left(q_{i}, l_{i}, \theta_{i}\right)-{ }_{\underline{\theta}}^{\theta_{i}} c_{\theta}(q, l, \theta)\left[\frac{F(\theta)}{F\left(\theta_{i}\right)}\right]^{n-1} d \theta \\
& q_{i}^{*}=\left(\frac{\omega_{1} \cdot S_{1} \cdot \theta_{i}}{k_{1} \cdot t_{1}}\right)^{\frac{1}{t_{1}-S_{1}}} \\
& l_{i}^{*}=L-\left(\frac{\omega_{2} \cdot S_{2} \cdot \theta_{i}}{k_{2} \cdot t_{2}}\right)^{\frac{1}{t_{2}-S_{2}}}
\end{aligned}
$$

As well as bid strategy value: $V_{i}=\frac{n-1}{n} v_{i}=\frac{n-1}{n}\left[p_{i}-c\left(q_{i}, l_{i}, \theta_{i}\right)\right]$ From Table 1, it can be seen that the supplier of the most advanced technology has the highest bid on margin and can eventually wins the auction. The expected return to the buyer from this mechanism is $\mathrm{EP}_{\text {buyer }}=0.9111929$. If the traditional method [17] is used, the expected return to the buyer is $E P_{B}=0.8817996$. At the time of delivery, the highest-quality supplier provides the highest quality of products with the shortest lead-time, which, although relatively expensive, is realistic. Hence, the example shows the effectiveness of the model.

Compared with the traditional model that uses the true utility of buyers as a scoring function, the final bid of buyers is shown in Table 2 below. 


\begin{tabular}{|c|c|c|c|c|}
\hline$\theta_{i}$ & $V_{i}$ & $P_{i}^{*}$ & $q_{i}^{*}$ & $I_{i}^{*}$ \\
\hline 0.09 & 0.0136114 & 0.1562792 & 0.0969947 & 0.9203006 \\
\hline 0.16 & 0.0164891 & 0.1893188 & 0.1169607 & 0.8830393 \\
\hline 0.22 & 0.0183357 & 0.2105206 & 0.1446245 & 0.8553755 \\
\hline 0.31 & 0.0205562 & 0.2360157 & 0.1817751 & 0.8182249 \\
\hline 0.42 & 0.022746 & 0.2611581 & 0.2225664 & 0.7774336 \\
\hline 0.56 & 0.0250352 & 0.2874416 & 0.2696199 & 0.7303801 \\
\hline 0.62 & 0.0258992 & 0.2973612 & 0.28855 & 0.71145 \\
\hline 0.73 & 0.0273483 & 0.3139988 & 0.3217426 & 0.6782574 \\
\hline 0.85 & 0.0287715 & 0.3303391 & 0.3561005 & 0.6438995 \\
\hline 0.97 & 0.0300663 & 0.3452054 & 0.388873 & 0.611127 \\
\hline
\end{tabular}

Table 1: Auction results of the margin bid.

\begin{tabular}{|c|c|c|c|c|c|c|c|c|c|c|}
\hline $\boldsymbol{\theta}_{i}$ & 0.09 & 0.16 & 0.22 & 0.31 & 0.42 & 0.56 & 0.62 & 0.73 & 0.85 & 0.97 \\
\hline $\boldsymbol{U}_{i}$ & 0.422 & 0.5112 & 0.5684 & 0.6372 & 0.7051 & 0.7761 & 0.8029 & 0.8478 & 0.8919 & 0.9321 \\
\hline $\boldsymbol{\Psi}_{i}$ & 0.4083 & 0.4947 & 0.5501 & 0.6167 & 0.6824 & 0.7511 & 0.777 & 0.8204 & 0.8631 & 0.902 \\
\hline
\end{tabular}

Table 2: Two auction methods to bring buyers results.

In addition, we can see from the examples and the proofs that the suppliers of least advanced technology have a low bid on the margin and the cost is high when the same project is completed. The suppliers of the most advanced technology have high bidding for the margin and the cost is low when the same project is completed. When the buyer intends to increase the threshold for the supplier to enter the auction system, the minimum margin $V_{0}$ may be appropriately raised, which constitutes the Spence-Mirrlees separation equilibrium. That is the suppliers of the least advanced technology do not participate in the auction, but lets the suppliers with better technology to participate in the auction.

Since, this mechanism satisfies the incentive compatibility constraint, this means that all types of suppliers are unwilling to hide the true technical information because doing so does not meet the goal of maximizing their own interests, so the mechanism can be implemented. In addition, the multi-attribute reverse auction bidding on margin does not need to build the scoring function, and the winner can guarantee the optimal non-price attribute value of the product through negotiation by using this method. Therefore, it not only retains the advantage of bidding in single-attribute auction, but also meets the requirements of non-price attributes in multi-attribute auction. Therefore, the model is more practical in nature.

\section{Conclusion}

Multi-attribute auction use scoring function to evaluate the attributes. However, the multi-attribute auction method of bidding on attributes increases the complexity of the design of the auction mechanism, making it relatively slow to develop. Although the singleattribute auction is simpler in design and implementation, it cannot satisfy the buyer's requirements for the multi-dimensional attributes of the product. Based on this, this paper combines the first-order sealed auction mechanism with the multi-attribute auction mechanism, and suggests a method to convert the multi-attribute auction into the single-attribute auction by bidding the margin by the suppliers. The method compels producers to bid on margin, causing them to compete in a first-order sealed auction based on the game logic. Since each supplier's bid on a balanced bid cannot exceed its net profit (which is the supplier's private information), so that margin's message contains the information about the technology type of the supplier.

When the buyer chooses the supplier who bid at the margin highest, which guarantees that the supplier has the most advanced technology.
Based on the supplier's bidding result of the margin and the's true technology information. Since these equilibrium property values are obtained by satisfying the constraints of supplier participation and incentive compatibility constraints, the rational suppliers will accept the buyers' requirements for each property of the products and successfully conduct the transaction. The main conclusions of this paper are:

(1) This method can make the multi-attribute auction easier to operate and implement while reducing the risk of supplier abandoning standard to cause transaction.

(2) It can ensure that the suppliers satisfy the incentive compatibility constraint and individual rational constraints, also he can win the auction with the developments in respect to advanced technology.

(3) The optimal transaction price and transaction quality that can be implemented will increase with the increase of technology types, and the delivery time will decrease as the type of technology increases.

(4) Compared with the existing traditional multi-attribute auction, this method can bring more expected benefits to buyers.

This method has greater applicability and can be directly extended to multi-attribute auction with dimension $n(n \geq 4)$. The shortcoming of this paper is that it implicitly supposes that suppliers and buyers are completely rational and have perfect recall ability, which may not be realistic. Follow-up research can relax the relevant assumptions and would result in greater number research activities in this field.

\section{References}

1. Schottmüller C, Boone J (2016) Procurement with specialized firms. Rand Journal of Economics 47: 661-687.

2. He H, Jian C (2010) Mechanism design on auctioning procurement contracts and bargaining. Journal of Management Sciences in China 13: 1-7.

3. Che YK (1991) Design Competition through Multidimensional Auction. Rand Journal of Economics 24: 668-680.

4. Leonardo R (2009) Biased Procurement auctions. Economic Theory 38: 169185.

5. Branco F (1997) The Design of Multidimensional Auction. Rand Journal of Economics 28: 63-81.

6. Jun L, Shulin L (2012) Multi-attribute procurement auction based on CobbDouglas utility function. Journal of Management Sciences in China 15: 54-60. 
Citation: Bashir MF (2018) A Class of Multi-attribute Auction Transformed into Single-Attribute Auction on Margin Bid. Bus Eco J 9: 352. doi: 10.4172/2151-6219.1000352

Page 8 of 8

7. Tian J, Chen Q (2014) Research on Profits Allocation between Supplier and Buyer with Risk-aversion in Multi-attribute Reverse Auction. Chinese Journal of Management Science 22: 33-39.

8. Fugger N, Katok E, Wambach A (2015) Collusion in dynamic buyer-determined reverse auction. Management Science 62: 518-533.

9. Ge Z, Whinston AB (2016) Mechanism design and Implementation of online multi-attribute procurement auction with the objective of maximizing social welfare. Management Review, pp: 47-60.

10. Kauffman RJ, Wood CA (2005) The effects of shilling on final bid prices in online auction. Electronic commerce research and Applications 4: 21-34.

11. Bichler M (2009) An experimental analysis of multi-attribute auction. Decision Support Systems 29: 249-268.

12. Chen-Ritzo CH, Harrison TP, Kwasnica AM, Thomas DJ (2005) Better, faster, cheaper: An experimental analysis of a multi-attribute reverse auction mechanism with restricted information feedback. Management Science 51: 1753-1762.

13. Li Z, Shao L, Sun D (2015) Designing Multi-Attribute Procurement Mechanisms for Assortment Planning. Decision Sciences 46: 597-622.

14. Optimal mechanism design for multi-unit online auction

15. Haruvy E, Katok E (2013) Increasing revenue by decreasing information in procurement auction. Production and Operations Management 22: 19-35.

16. Karlsson N (2016) Control problems in online advertising and benefits of randomized bidding strategies. European Journal of Control 30: 31-49.

17. David E, Azoulay-Schwartz R, Kraus S (2006) Bidding in sealed-bid and English multi-attribute auction. Decision Support Systems 42: 527-556.

18. Yahui S, Yuqiang F (2010) Multi-attribute sealed-bid auction model and optimal bidding strategies. Systems Engineering-Theory \& Practice 30: 1185-1189.

19. Vickrey W (1961) Counterspeculation, auction, and competitive sealed tenders The Journal of finance 16: 8-37.

20. Myerson RB (1981) Optimal auction design. Mathematics of operations research 6: 58-73.
21. Riley JG, Samuelson WF (1981) Optimal auction. The American Economic Review 71: 381-392.

22. Asker J, Cantillon E (2004) Equilibrium in scoring auction. FEEM working paper

23. Xianke Z, Yuqiang F (2015) Bidding strategies and revenue analysis for reverse multi-attribute auction. Journal of Management Sciences in China 18: 24-33.

24. Shengbao $Y$ (2013) Research on multi-attribute English aution based on power utility functions. Chinese Journal of Management Science 21: 132-138.

25. Kersten GE (2014) Multi-attribute Procurement Auction: Efficiency and Social Welfare in Theory and Practice. Decision Analysis 11: 215-232.

26. Xueguang Z, Long R (2016) Game model on multi-attribute reverse auction with costly bid. Chinese Journal of Management Science 24: 134-142.

27. Beil DR, Wein LM (2003) An inverse-optimization-based auction mechanism to support a multi-attribute RFQ process. Management Science 49: 1529-1545.

28. Yang N, Liao X, Huang WW (2014) Decision support for preference elicitation in multi-attribute electronic procurement auction through an agent-based intermediary. Decision Support Systems 57: 127-138.

29. Wang M, Liu S (2014) Equilibrium bids in practical multi-attribute auction Economics Letters 123: 352-355.

30. Wang $H$ (2013) Contingent payment auction mechanism in multidimensiona procurement auction. European Journal of Operational Research 224: 404-413.

31. Holmström B (1979) Groves' scheme on restricted domains. Econometrica Journal of the Econometric Society, pp: 1137-1144.

32. Myerson RB (2013) Game theory. Harvard university press.

33. Kaplan TR, Zamir S (2012) Asymmetric first-price auction with uniform distributions: analytic solutions to the general case. Economic Theory 50: 269 302 .

34. Morales DR, Steinberg R (2014) Revenue deficiency under second-price auction in a supply-chain setting. European Journal of Operational Research 233: $131-144$.

35. Araujo A, Moreira H (2010) Adverse selection problems without the SpenceMirrlees condition. Journal of Economic Theory 145: 1113-1141. 